\title{
Adölesanlarda Sağlık Okuryazarlığı ve Beslenme Okuryazarlığının Diyet Kalitesine Etkisi
}

\author{
Münire Kırşan ${ }^{1 *}$, Burcu Ateş Özcan ${ }^{2}$ \\ 1* İstanbul Okan Üniversitesi, Sağlık Bilimleri Enstitüsü, Beslenme ve Diyetetik Bölümü, İstanbul, Türkiye, (ORCID: 0000-0002-5079-9653), \\ mnr.dastan@hotmail.com \\ 2 İstanbul Okan Üniversitesi, Sağlık Bilimleri Fakültesi, Beslenme ve Diyetetik Bölümü, İstanbul, Türkiye (ORCID: 0000-0003-2627-0167), burcu.ozcan@ okan.edu.tr
}

(İlk Geliş Tarihi 03 Temmuz 2021 ve Kabul Tarihi 09 Eylül 2021)

(DOI: $10.31590 /$ ejosat.962135)

ATIF/REFERENCE: Kırşan, M. \& Ateş Özcan, B. (2021). Adölesanlarda Sağlık Okuryazarlığı ve Beslenme Okuryazarlığının Diyet Kalitesine Etkisi. Avrupa Bilim ve Teknoloji Dergisi, (27), 532-538.

Öz

Sağlık okuryazarlığı ve beslenme okuryazarlığı son zamanlarda gittikçe popüler hale gelirken, konu hakkında yeterli çalışma bulunmaması ilgili çalışmalara ihtiyaç duyulduğunu göstermektedir. Bu çalışma adölesanların sağlık okuryazarlığı ve beslenme okuryazarlığı düzeylerinin diyet kalitesine etkilerinin incelenmesi amacıyla yapılmıştır. Çalışma özel bir lisede $2020-2021$ güz döneminde eğitim-öğrenim gören 15-19 yaş arası 70’i erkek, 158'i kız toplamda 228 adölesan ile yürütülmüştür. Katılımcılara anket formu, sağlık okuryazarlığı ölçeği (SOY-32), beslenme okuryazarlığı ölçeği (BOY) ve Akdeniz diyeti kalite indeksi (KIDMED) uygulanmıştır. Çalışmaya katılan öğencilerin yaş ortalamaları 16,23 $\pm 1,09$ yıl, BKİ ortalamaları $21,25 \pm 3,49 \mathrm{~kg} / \mathrm{m}^{2}$ dir. Katılımciların ortalama SOY-32 puanı 15,24 \pm 10,25 puan (yetersiz düzey), ortalama BOY puanı 60,88 $\pm 18,53$ puan (orta düzey), ortalama KIDMED puanı 6,6 2,17 puandır (orta diyet kalitesi, diyette iyileştirme gerekli). SOY-32 ile BOY puanları arasında zayıf derecede pozitif yönlü anlamlı $(\mathrm{p}<0,001)$, diyet kalitesi ile negatif yönlü $(\mathrm{p}>0,05)$, BOY ile diyet kalitesi arasında ise pozitif yönlü $(\mathrm{p}=0,073)$ ilişkiler saptanmıştır. Beslenme okuryazarlığı puanının 1 birim artması ile diyet kalitesi puanının 0,018 birim arttığı, SOY32 puanının 1 birim artması ile diyet kalitesinin 0,012 puan azaldığı saptanmıştır. Öğrencilerin \%38,6'sının beslenme ve sağlı bilgilerini edindiği kaynağın televizyon, radyo, internet olduğu, \%27,2'sinin aile, arkadaş ve sadece \%7,5'inin diyetisyen, \%2,6'sının doktor ve sağlık çalışanı olduğu gözlenmiştir. Çalışmada adölesanların sağlık okuryazarlığ 1 , beslenme okuryazarlığı ve diyet kalitesi düzeyleri ve etkileri beklenenin altındadır. Bunun sebebinin, öğrencilerin doğru bilgi kaynaklarına ulaşamamaları veya bilgiyi hayata geçirmede sıkıntı yaşamaları olabileceği düşünüldüğünden sağlık ve beslenme bilgilerinin doğru kaynaklar ile öğrencilere ulaştırılması ve bunlarla ilgili eğitimlerin öğrencilere verilmesi önerilmektedir.

Anahtar Kelimeler: Sağlık okuryazarlığı, Beslenme okuryazarlığı, Diyet kalitesi.

\section{The Effect of Health Literacy and Nutrition Literacy on Diet Quality in Adolescents}

\begin{abstract}
While health literacy and nutritional literacy have become increasingly popular recently, the lack of sufficient studies on the subject shows that there is a need for relevant studies. This study was conducted to examine the effects of adolescents' health literacy and nutritional literacy levels on diet quality. The study was conducted with a total of 228 adolescents, 70 boys and 158 girls, between the ages of 15-19, studying in a private high school in the fall semester of 2020-2021. A questionnaire, health literacy scale (HLS-32), nutritional literacy scale (NLSA) and Mediterranean diet quality index (KIDMED) were applied to the participants. The average age of the students participating in the study was $16.23 \pm 1.09$ years, the average BMI was $21.25 \pm 3.49 \mathrm{~kg} / \mathrm{m}^{2}$. The mean HLS-32 score of the participants was $15.24 \pm 10.25$ points (unsatisfactory), the mean NLSA score was $60.88 \pm 18.53$ points (intermediate level), the mean KIDMED score was 6.6 \pm 2.17 points (moderate diet quality, improvement in diet needed). There were weakly positive and significant $(\mathrm{p}=<0.001)$ correlations between HLS-32 and NLSA scores, negative correlations with diet quality ( $\mathrm{p}>0.05)$, and positive correlations between NLSA and diet quality $(\mathrm{p}=0.073)$. It was determined that with 1 unit increase in nutritional literacy score, diet quality score increased by 0.018 units, and with 1 unit increase in HLS-32 score, diet quality decreased by 0.012 points. It was
\end{abstract}

*Sorumlu Yazar: burcu.ozcan@okan.edu.tr 
determined that $38.6 \%$ of the students obtained their nutrition and health information from television, radio and internet, $27.2 \%$ obtained from family and friends, only $7.5 \%$ obtained from dietitians, $2.6 \%$ obtained from doctors and health frofessionals. In the study, the health literacy, nutritional literacy and diet quality levels and effects of the adolescents were lower than expected. Since it is thought that the reason for this may be that the students cannot reach the right information sources or have difficulties in implementing the information, it is recommended that the health and diet information be delivered to the students with the right resources and that related educations should be given to the students.

Keywords: Health literacy, Nutrition literacy, Diet quality.

\section{Giriş}

Sağlıklı bir toplumun temelinde sağlıklı beslenme ve yaşam tarzı yer almaktadır (Dima-Cozma ve ark., 2014; Carbone ve Zoellner, 2012). Özellikle genç yaşlarda sağlıklı beslenme ve fiziksel aktivite alışkanlıkları kazanmak önceliklidir. Bununla birlikte adölesanlarda sağlıksız beslenme alışkanlıkları ve davranışları sık gözlenebilmektedir (Rodrigues ve ark., 2017). $\mathrm{Bu}$ kapsamda adölesanların sağlıklı beslenme ile ilgili bilgilerinin yetersiz olduğunu gösteren çalışmalar mevcuttur (Naeeni ve ark., 2014; Saribay ve Kirbas, 2019). Ek olarak, adölesanların sağlık okuryazarlığı ve beslenme okuryazarlığı düzeylerinin de düşük ve yetersiz olduğu gözlenmiştir (Chang, 2011; Manganello, 2008). Oysaki insanların sağlık okuryazarlığ ve beslenme okuryazarlığı seviyelerinin arttırılması sağlıklı bir toplumun oluşumuna katkı sağlayabilmektedir (Dima-Cozma ve ark., 2014; Carbone ve Zoellner, 2012).

Sağlık okuryazarlığı (SOY), bireylerin sağlıklı olma ve sağlığın korunması için sağlıkla ilgili bilgiye ulaşması, bilgiyi anlaması ve kullanma becerisi olarak tanımlanmıştır (Joulaei ve ark., 2018). Yaş, meslek, eğitim düzeyi, gelir düzeyi gibi demografik verilere kıyasla sağlık okuryazarlığının sağlık açısından önemli bir parametre olduğu düşünülmektedir (DimaCozma ve ark., 2014). SOY düzeyinin düşük olması, bireylerin tanı ve tedavileri üzerinde olumsuz etkiler göstererek hastane yatışlarının uzamasına sebep olabilmektedir (Berkman ve ark., 2011). Beslenme okuryazarlığı (BOY) ise bireylerin beslenme bilimindeki bilgilere erişme, bu bilgileri benimseme ve yorumlama, ardından konu ile ilgili doğru seçimler yapabilme yeteneği kazanma, önerilen şekilde porsiyon seçimi sağlama ve sağlıklı besin seçimi ve tüketimi, sağlıklı beslenmeyi öğrenme ve sürdürme, diyet kalitesinin artırılması ve sürekliliği, besin sistemlerinin işleyişini anlayıp değerlendirme ve besin güvencesinin sağlanması, sürdürülmesi açısından önemli ve gerekli olan, bilgi, beceri, istek, karar alma ve verme, tutum davranış ve yeteneklerinin olmasıdır (Vidgen ve Gallegos, 2014; Kolasa ve ark., 2001). Sağlıklı beslenme ve sağlık alışkanlıklarının öneminin anlaşılması ileride yaşanabilecek sağlık problemlerinin ve global sağlık sorunlarının önlenebilmesi açısından önemlidir (Mansfield ve ark., 2020). Bu açıdan eldeki veriler, daha sağlıklı beslenmek ve beslenme alışkanlıkları kazanmak açısından beslenme okuryazarlığının arttırılmasının önemli olduğunu vurgulamaktadır (Carbone ve Gibbs, 2013).

Sağlık okuryazarlığı çalışmaları yiyecek ve beslenmeye odaklanmıyor olsa da beslenme okuryazarlığı ve sağlık okuryazarlığı iç içedir (Carbone ve Zoellner, 2012; Silk ve ark., 2008). Yapılan bir çalışmada düşük sağlık okuryazarlığı, düşük diyet kalitesi ile ilişkili bulunmuştur (Kuczmarski ve ark., 2016). Beslenme okuryazarlığı ve diyet kalitesinin karşılaştırıldığ başka bir çalışmada ise artan beslenme okuryazarlığı daha az şeker tüketimi, daha fazla süt ürünü tüketimi ve daha iyi bir enerji dengesi ile ilişskili bulunmuştur (Joulaei ve ark., 2018).
Tüm bu sonuçlar SOY ve BOY'un önemini vurgularken birbirleri arasındaki ilişki ve diyet kalitesi üzerine etkilerinin belirlendiği çalışmalar bildiğimiz kadarıyla bulunmamaktadır. Bu çalışmada da SOY ve BOY arasındaki ilişki ve her ikisinin diyet kalitesi üzerindeki etkilerinin belirlenmesi amaçlanmıştır.

\section{Materyal ve Metot}

\subsection{Katılımcılar ve Prosedür}

Kesitsel-tanımlayıcı tipteki bu çalışma 228 adölesan ile tamamlanmıştır. Çalışmanın yürütülmesi için ilgili okul yönetiminden yazılı onay alındıktan sonra İstanbul Okan Üniversitesi Girişimsel Olmayan Klinik Araştırmalar Etik Kurulu'ndan 07.10.2020 tarih ve 2 karar numaralı etik kurul onayı alınmıştır. Çalışmaya katılmayı kabul eden öğrencilerin ailelerine "Veliler İçin Gönüllü Onam Formu", kendilerine "Öğrenci Gönüllü Onam Formu” okutulup imzalatılmıştır. Çalışmanın verileri, etik kurul onayını takiben 1 aylık süre içerisinde online anket olarak toplanmıştır. Mevcut COVİD-19 Pandemisi sürecinden ötürü Milli Eğitim Bakanlığı tarafından eğitimin online devam etmesine karar verilmesi sebebi ile veriler online ortamda toplanmıştır.

\subsection{Veri Toplama Araçları}

Katılımcılara antropometrik ölçümleri ve kişisel bilgilerinin sorgulandığı bir anket formu, SOY'un belirlenmesinde "Türkiye Sağlık Okuryazarlığı Ölçeği-32” (TSOY-32), BOY'un belirlenmesinde "Adölesan Beslenme Okuryazarlığı Ölçeği" (Nutrition Literacy Status of Adolescent Students, BOY), diyet kalitesinin belirlenmesinde “Akdeniz Diyeti Kalite İndeksi”nden (KIDMED) faydalanılmıştır. TSOY-32, Okyay ve arkadaşları (Okyan ve Abacıgil, 2016) tarafindan 2016 yılında Avrupa Sağlık Okuryazarlığı Çalışması (Health Literacy Europe, HLSEU) baz alınarak geliştirilen bir ölçektir. Geçerlilik ve güvenirliği Sağlık Bakanlığı tarafindan test edilmiş ve onaylanmıştır (Cronbach Alfa katsayısı: 0.927). En düşük 0, en yüksek 50 puan alınabilen ölçeğin puanları arttıkça sağlık okuryazarlığı da artmaktadır. Ölçekten elde edilen puan 0- 25 aras1 ise bireylerde "yetersiz düzeyde", 26- 33 aras1 ise "sorunlu (sınırl1) düzeyde", 34- 42 arası ise "yeterli düzeyde", 43- 50 aras1 ise "mükemmel düzeyde" sağlık okuryazarlığ1 olduğu görülmektedir (Okyan ve Abacıgil, 2016). BOY, 2012 yılında Bari (Bari, 2012) tarafından geliştirilmiş olup Türkçe validasyon çalışmasını 2017 yılında Türkmen ve ark. (Türkmen ve ark., 2017) gerçekleştirmiştir (Cronbach Alfa katsayısı: 0.80). Üç alt boyutu olan ölçek toplamda 22 maddeden oluşmaktadır ve herhangi bir kesme noktası bulunmamaktadır. Ölçekten minimum 22 puan, maksimum 110 puan alınmakta olup toplam puan arttıkça beslenme okuryazarlığı da artmaktadır (Türkmen ve ark., 2017). Serra-Majem ve ark. (Serra-Majem ve ark., 2004) 16 sorudan meydana gelen KIDMED'i geliştirmiştir. Ölçekten minimum sifir puan, maksimum 12 puan alınmaktadır. Sekiz ve üstü puan alımı diyet kalitesinin optimal düzeyde olduğunu, 4- 7 puan alımı diyet kalitesinin orta düzeyde (diyette iyileştirme 
gerekli) olduğunu, 3 ve altı puan alımı ise diyet kalitesinin çok düşük olduğunu göstermektedir.

\section{3. İstatistiksel Analiz}

Verilerin analizi için SPSS 21 programı kullanılmıştır. Tanımlayıcı istatistikler minimum ve maksimum, ortalama ve standart sapma ile ifade edilmiştir. Sürekli değişkenlerin normal dağılıma uygunluğu Shapiro Wilk testi ile kontrol edilmiştir. Normal dağılan değişkenlerde, iki grup ortalamasının karşılaştırılmasında Student's t test kullanılmıştır. İkiden fazla grup ortalamasının karşılaştırmasında ise Tek Yönlü Varyans Analizi, post hoc testlerden ise Tukey kullanılmıştır. Normal dağılmayan değişkenlerde ortalamaların karşılaştırılmasında Mann Whitney U testi kullanılmıştır. Sürekli değişkenler arasında doğrusal ilişki incelenmesinde, normal dağılım gösteren veriler için Pearson Korelasyon, normal dağılmayan veriler için ise Spearman Rho katsayıları hesaplanmıştır. Diyet kalitesini etkileyen faktörler Tek değişkenli analizler ile belirlenmiş olup Çoklu Doğrusal Regresyon modeli kurulmuştur. Açıklayıcılık kastayısı (R2) ve Beta katsayılarıyla, oluşan modelin sonuçları ifade edilmiştir. Ki-Kare testi kategorik değişkenlerin analizinde kullanılmıştır. İstatistik anlamlılık düzeyi 0.05 alınmıştır.

\section{Araştırma Sonuçları ve Tartışma}

Çalışmada SOY ve BOY düzeyleri ile aralarındaki ilişkinin saptanması ve bunların diyet kalitesine etkisinin belirlenmesi amaçlanmıştır. Çalışma, özel bir lisede 2020-2021 güz döneminde eğitim-öğrenim gören 15-19 yaş arası 70'i erkek, 158'i kız toplamda 228 adölesan ile yürütülmüştür.

Çalışmaya katılan öğencilerin yaş ortalamaları $16.23 \pm 1.09$ y1l, BKİ ortalamaları $21.25 \pm 3.49 \mathrm{~kg} / \mathrm{m}^{2}$ ' dir $\left(\right.$ BKİ $_{\text {erkek}}: 22.7 \pm$ $\left.4.33 \mathrm{BKI}_{\mathrm{kzz}}: 20.62 \pm 2.83, \mathrm{p}<0.001\right)$. Kı̈ öğrencilerin çoğunluğu (\%44.3) BKİ değerlendirmesine göre zayıf, \%29.7'si normal, $\% 14.6$ 's1 çok zayıf, \%9.5'i hafif kilolu ve \%1.9'u obez iken erkek öğrencilerin çoğunluğu (\%31.4) hafif kilolu, \%8.6's1 obez, $\% 21.4$ 'ü normal, \%27.1'i zayıf ve \%11.4'ü çok zayıftır $(\mathrm{p}<0.001)$ (tabloda verilmemiştir)

Adölesanların sosyodemografik ve genel özelliklerine göre dağılımı tablo 1'de verilmiştir. Katılımcıların \%30.7'si erkek, \%69.3'ü kızdır. Adölesanların beslenme, diyet ve sağlık bilgilerini aldıkları kaynaklara göre \%38.6'ının kaynağı TV, radyo, internet, \%27.2'sinin aile ve arkadaş, \%7.5'inin diyetisyen ve \%2.6'sı doktor ve sağlık çalışanıdır (Tablo 1). Yapılan bir çalışmada, beslenme bilgisini sağlık çalışanlarından edinen 18-25 yaş arası bireylerin daha yüksek beslenme bilgisi edindiği görülmüştür (Quaidoo ve ark., 2018). Beslenme bilgisi ise sağlık okuryazarlığının ayrılmaz bir ögesidir ve düşük sağlık okuryazarlığının kötü sağlık sonuçları oluşturduğu belirtilmektedir (Spronk ve ark., 2014). Bu çalışmada da bilgi kaynağına göre SOY, BOY ve KIDMED puanları incelendiğinde

Tablo 1. Öğrencilerin sosyodemografik ve genel özellikleri

\begin{tabular}{|c|c|c|c|}
\hline & & $\mathrm{N}: 228$ & Yüzde (\%) \\
\hline \multirow{2}{*}{ Cinsiyet } & $\mathrm{K} 1 \mathrm{z}$ & 158 & 69.3 \\
\hline & Erkek & 70 & 30.7 \\
\hline \multirow{6}{*}{$\begin{array}{l}\text { Öğrencilerin annelerinin eğitim } \\
\text { düzeyi }\end{array}$} & Okur-yazar & 3 & 1.3 \\
\hline & İlkokul mezunu & 78 & 34.2 \\
\hline & Ortaokul mezunu & 43 & 18.9 \\
\hline & Lise mezunu & 63 & 27.6 \\
\hline & Lisans mezunu & 37 & 16.2 \\
\hline & Lisansüstü (yüksek lisans, doktora) mezunu & 4 & 1.8 \\
\hline \multirow{6}{*}{ Eğitim düzeyi } & Okur-yazar & 4 & 1.8 \\
\hline & İlkokul mezunu & 57 & 25.0 \\
\hline & Ortaokul mezunu & 41 & 18.0 \\
\hline & Lise mezunu & 63 & 27.6 \\
\hline & Lisans mezunu & 54 & 23.7 \\
\hline & Lisansüstü (yüksek lisans, doktora) mezunu & 9 & 3.9 \\
\hline \multirow{6}{*}{ Ö̆grencilerin annelerinin mesleği } & İşçi & 26 & 11.4 \\
\hline & Memur & 20 & 8.8 \\
\hline & Esnaf & 1 & 0.4 \\
\hline & Emekli & 2 & 0.9 \\
\hline & Çalışmıyor, ev hanımı & 159 & 69.7 \\
\hline & Hayatta değil & 20 & 8.8 \\
\hline \multirow{7}{*}{ Ö̈̆rencilerin babalarının mesleği } & İşçi & 50 & 21.9 \\
\hline & Memur & 21 & 9.2 \\
\hline & Esnaf & 50 & 21.9 \\
\hline & Çiftçi & 3 & 1.3 \\
\hline & Emekli & 8 & 3.5 \\
\hline & Çalışmıyor, ev hanımı & 4 & 1.8 \\
\hline & Hayatta değil & 92 & 40.4 \\
\hline \multirow{7}{*}{$\begin{array}{l}\text { Öğrencilerin beslenme ve sağlık } \\
\text { bilgilerini edindikleri kaynaklar }\end{array}$} & Kitap, kütüphane & 16 & 7.0 \\
\hline & Aile, arkadaşlar & 62 & 27.2 \\
\hline & Radyo, televizyon, internet & 88 & 38.6 \\
\hline & Diyetisyen & 17 & 7.5 \\
\hline & Doktor, sağl1k çalışan1 & 6 & 2.6 \\
\hline & Alternatif tıpla uğraşanlar & 29 & 12.7 \\
\hline & Gazete & 10 & 4.4 \\
\hline \multirow{2}{*}{ Sigara kullanım durumu } & Kullanıyor & 19 & 8.3 \\
\hline & Kullanmiyor & 209 & 91.7 \\
\hline
\end{tabular}


en yüksek puanlar, bilgi kaynağı diyetisyen olanlarda gözlenmiştir. $\mathrm{Bu}$ fark $\mathrm{BOY}$ grubunda istatistiksel olarak önemlidir ( $\mathrm{p}<0.001)$ (Tablo 3). Ancak bu bilgiyi diyetisyenden edinme oranının (\%7.5) düşüklüğü göz önünde bulundurulduğunda, öğrencilerin doğru bilgiye doğru kaynaktan ulaşabilmesi açısından yönlendirilmesi önerilmektedir. Ek olarak, internette çok miktarda bilimsel ve bilimsel olmayan bilgi, taraflı reklam ve haber bulunmaktadır. Ancak gençlerin neredeyse hiç bilimsel verilere başvurmadığı bilinmektedir. $\mathrm{Bu}$ doğrultuda, adölesanların geçerli bilgilere nasıl ve nereden ulaşabilecekleri konusunda eğitilmeleri önemlidir (Joulaei ve ark., 2018).

Katılımcıların ortalama SOY-32 puanı $15.24 \pm 10.25$ puan (yetersiz düzey) olup erkeklerin puan ortalaması kız öğrencilerden daha yüksektir $(\mathrm{p}<0.05)$. Öğrencilerin çoğunluğunun (\%89) SOY'u yetersiz iken \%6.1'inin sorunlu, \%2.6'ının yeterli, \%2.2'sinin mükemmeldir (Tablo 2). Sağlık okuryazarlıkları seviyelerinin belirlenmesi amacıyla 870 öğrenci ile yürütülmüş bir çalışmada, öğrencilerin \%62.8'inin SOY düzeyinin yeterli ve mükemmel düzeyde olduğu saptanmış olup SOY düzeylerinin erkeklere kıyasla kadınlarda daha yüksek olduğu bulunmuştur (Malatyalı ve Biçer, 2018). Adölesanlarda SOY ile riskli sağlık davranışlarının incelendiği bir başka çalışmada ise öğrencilerin SOY-32 puan ortalaması $34.35 \pm 8.70$ puan bulunmuştur. Çalışmada kıların SOY-32 puan ortalamasının erkeklere kıyasla daha yüksek olduğu görülmüştür $(\mathrm{p}=0.018)$. Çalışmaya göre sağlık okuryazarlığı puanlarının düşüklügü adölesanlarda görülen riskli sağlık davranışlardan ileri geldiğini göstermektedir. $\mathrm{Bu}$ davranışları azaltmak için sağlık okuryazarlık seviyelerini yükseltecek uygulamaların yapılması önerilmiştir (Koçak ve Demir, 2019).

Tablo 2. Ögrencilerin SOY, BOY ve KIDMED puan ortalamaları ve dăğlımları

\begin{tabular}{|c|c|c|c|c|c|c|c|}
\hline & \multicolumn{2}{|c|}{ Erkek (n:70) } & \multicolumn{2}{|c|}{ K1z (n:158) } & \multicolumn{2}{|c|}{ Toplam (n:228) } & \multirow{2}{*}{$\mathbf{p}$} \\
\hline & Ort \pm SS & Alt- Üst & Ort \pm SS & Alt- Üst & Ort \pm SS & Alt- Üst & \\
\hline SOY puanı & $17.29 \pm 11.29$ & $0.52-50$ & $14.33 \pm 9.64$ & $0-43.23$ & $15.24 \pm 10.25$ & $0-50$ & 0.044* \\
\hline BOY puanı & $56.87 \pm 17.93$ & $22-102$ & $62.65 \pm 18.57$ & $22-110$ & $60.88 \pm 18.53$ & $22-110$ & 0.029* \\
\hline \multirow[t]{2}{*}{ KİDMED puanı } & $6.59 \pm 2.06$ & $3-12$ & $6.61 \pm 2.23$ & $1-12$ & $6.6 \pm 2.17$ & $1-12$ & 0.944 \\
\hline & $\mathbf{n}$ & $\%$ & $\mathbf{n}$ & $\%$ & $\mathbf{n}$ & $\%$ & \\
\hline \multicolumn{8}{|l|}{ SOY sinıflaması } \\
\hline Yetersiz & 58 & 82.9 & 145 & 91.8 & 203 & 89.0 & \multirow{4}{*}{0.061} \\
\hline Sorunlu & 5 & 7.1 & 9 & 5.7 & 14 & 6.1 & \\
\hline Yeterli & 3 & 4.3 & 3 & 1.9 & 6 & 2.6 & \\
\hline Mükemmel & 4 & 5.7 & 1 & 0.6 & 5 & 2.2 & \\
\hline \multicolumn{8}{|l|}{ KİDMED sınıflaması } \\
\hline Çok düşük diyet kalitesi & 4 & 5.7 & 13 & 8.2 & 17 & 7.5 & \multirow{3}{*}{0.705} \\
\hline Diyete müdahale gerekli & 46 & 65.7 & 96 & 60.8 & 142 & 62.3 & \\
\hline Optimal diyet & 20 & 28.6 & 49 & 31.0 & 69 & 30.3 & \\
\hline
\end{tabular}

Literatürde adölesanların beslenme okuryazarlığı düzeylerine yönelik sınırlı çalışma bulunmaktadır. Sağlık okuryazarlığı ve beslenme okuryazarlığı pek çok konuda örtüşebilmektedir. Dolayısı ile yapılan çalışmalarda sıklıkla sağlık okuryazarlığ ile ilgili incelemeler göz önünde bulundurulmuştur (Silk ve ark., 2008). Ancak, literatürde SOY düzeylerinin belirlenmesinde kullanılan ölçeklerin BOY düzeylerinin saptanmanmasında yeterli olmayacağı kanısı yer almaktadır (Gibbs HD ve Chapman-Novakofski, 2012). Bu çalışmada SOY-32 ile BOY puanları arasında zayıf derecede pozitif yönlü anlamlı $(\mathrm{p}<0.001)$ bir ilişki saptanmıştır (Tablo 4). Adölesanların beslenme okuryazarlığının belirlendiği bir çalışmada beslenme okuryazarlığı orta düzeyde bulunmuş, kızlarda BOY ortalama puanının daha yüksek olduğu tespit edilmiştir ( $\mathrm{p}=0.02)$. (Bari, 2012). Bu çalışmada da katılımcıların ortalama ortalama BOY puanı $60.88 \pm 18.53$ puan (orta düzey) olup kızların puanı erkeklerden daha yüksektir $(p=0.029)$ (Tablo 2). Adölesanlar ve genç yetişkinler arasında BOY durumunu ve bunun diyet alımının niceliği ve kalitesi ile ilişkisini incelemek, bu yaş gruplarında beslenme sağlığını geliştirmede önemli stratejilerin benimsenmesinde faydalı olabilmektedir (Joulaei ve ark., 2018).
Akdeniz Tipi Beslenme, yeterli ve dengeli beslenme açısından global olarak önerilen, en iyi ve dengeli beslenme modellerinden biridir. Akdeniz tipi beslenme, özellikle kardiyovasküler hastalıkların diğer ülkelere kıyasla Akdeniz ülkelerinde daha düşük sıklıkta görülmesinin fark edilmesi ile iyice ön plana çıkmıştır (Bayındır Gümüş ve Yardımcı, 2020). $\mathrm{Bu}$ doğrultuda KİDMED, sağlıklı beslenmenin bir parametresi olarak kullanılan geçerli ve uygulaması kolay bir yöntemdir (Serra-Majem ve ark., 2004). Bu çalışmada öğrencilerin KIDDMED ortalama değeri $6.6 \pm 2.17$ puandır (orta düzey diyet kalitesi, diyette iyileştirmenin gerekli olduğu düzey). Öğrencilerin \%30.3'ünün optimal diyet kalitesi düzeyine, $\% 62.3$ 'ünün orta diyet kalitesi düzeyine, \%7.5'inin çok düşük diyet kalitesi düzeyine sahip oldukları bulunmuştur.

On dört, on sekiz yaş arası 550 adölesanda diyet kalitesini etkileyen faktörlerin incelendiği bir çalışmada ortalama diyet kalitesi $5.12 \pm 2.40$ puan bulunmuştur. Çalışmada adölesanların BKİ ile KİDMED puanları arasında pozitif yönlü anlamlı ilişkiler saptanmıştır (Ateş Özcan ve ark., 2020). Yapılan çalışmalarda beslenme temelli SOY'un yağ alımı ve sağlıksız beslenme ile negatif ilişkili olduğu bulunmuştur (Smith, 2009; Vaitkeviciute ve ark., 2015). Adölesanlarda BOY ve diyet 535 
kalitesinin ilişkisinin araştırıldı̆̆ı başka bir çalışmada ise BOY ve diyet kalitesinin istatistiksel olarak anlamlı şekilde ilişkili olduğu bulunmuştur (Joulaei ve ark., 2018). Bu çalışmada ise BOY ile diyet kalitesi arasında pozitif yönlü anlamsız $(\mathrm{p}=0.073)$ ilişkiler saptanmıştır (Tablo 4). Ek olarak beslenme okuryazarlığ puanının 1 birim artması ile diyet kalitesi puanının 0.018 birim arttığı, SOY-32 puanının 1 birim artması ile diyet kalitesinin 0.012 puan azaldığı saptanmıştır (Tablo 5).

Tablo 3. Öğrencilerin să̆lık, beslenme ve diyet ile ilgili bilgileri edinme kaynaklarına göre SOY, BOY ve KIDMED puan ortalama değerleri

\begin{tabular}{|c|c|c|c|c|}
\hline & Edinilen bilginin kaynağı & Ort \pm SS & Alt- Üst & $\mathbf{p}$ \\
\hline \multirow{7}{*}{ SOY puanı } & Kütüphane, kitap & $9.04 \pm 7.9$ & $0.52-21.88$ & \multirow{7}{*}{0.161} \\
\hline & Aile, arkadaşlar & $15.92 \pm 11.68$ & $0.52-50$ & \\
\hline & Radyo, televizyon, internet & $16.00 \pm 10.24$ & $0-48.48$ & \\
\hline & Diyetisyen & $17.67 \pm 8.91$ & $1.04-31.72$ & \\
\hline & Doktor, sağlık çalışanı & $15.63 \pm 12.4$ & $0-28.65$ & \\
\hline & Alternatif tıpla uğraşanlar & $14.82 \pm 8.17$ & $2.08-29.76$ & \\
\hline & Gazete & $11.18 \pm 7.96$ & $0-22$ & \\
\hline \multirow{7}{*}{ BOY puanı } & Kitap, kütüphane & $49.5 \pm 22.04$ & $22-80$ & \multirow{7}{*}{$<0.001 *$} \\
\hline & Aile, arkadaşlar & $54.9 \pm 20.25$ & $22-102$ & \\
\hline & Radyo, televizyon, internet & $66.19 \pm 14.94$ & $27-110$ & \\
\hline & Diyetisyen & $66.45 \pm 16$ & $30-103$ & \\
\hline & Doktor, sağlık çalışanı & $64.12 \pm 18.43$ & $33-88$ & \\
\hline & Alternatif tıpla uğraşanlar & $44.17 \pm 1.17$ & $42-45$ & \\
\hline & Gazete & $57.7 \pm 21.01$ & $27-95$ & \\
\hline \multirow{7}{*}{ KIDMED puanı } & Kitap, kütüphane & $5.69 \pm 1.78$ & $4-10$ & \multirow{7}{*}{0.204} \\
\hline & Aile, arkadaşlar & $6.66 \pm 2.04$ & $1-12$ & \\
\hline & Radyo, televizyon, internet & $6.5 \pm 2.1$ & $2-11$ & \\
\hline & Diyetisyen & $7.28 \pm 2.02$ & $1-12$ & \\
\hline & Doktor, sağlık çalışanı & $7.59 \pm 2.21$ & $3-11$ & \\
\hline & Alternatif tıpla uğraşanlar & $5.83 \pm 4.4$ & $3-12$ & \\
\hline & Gazete & $5.4 \pm 2.01$ & $3-10$ & \\
\hline
\end{tabular}

Tablo 4. Öğrencilerin SOY, BOY ve KIDMED puanlarının bazı değerler ile ilişkisi

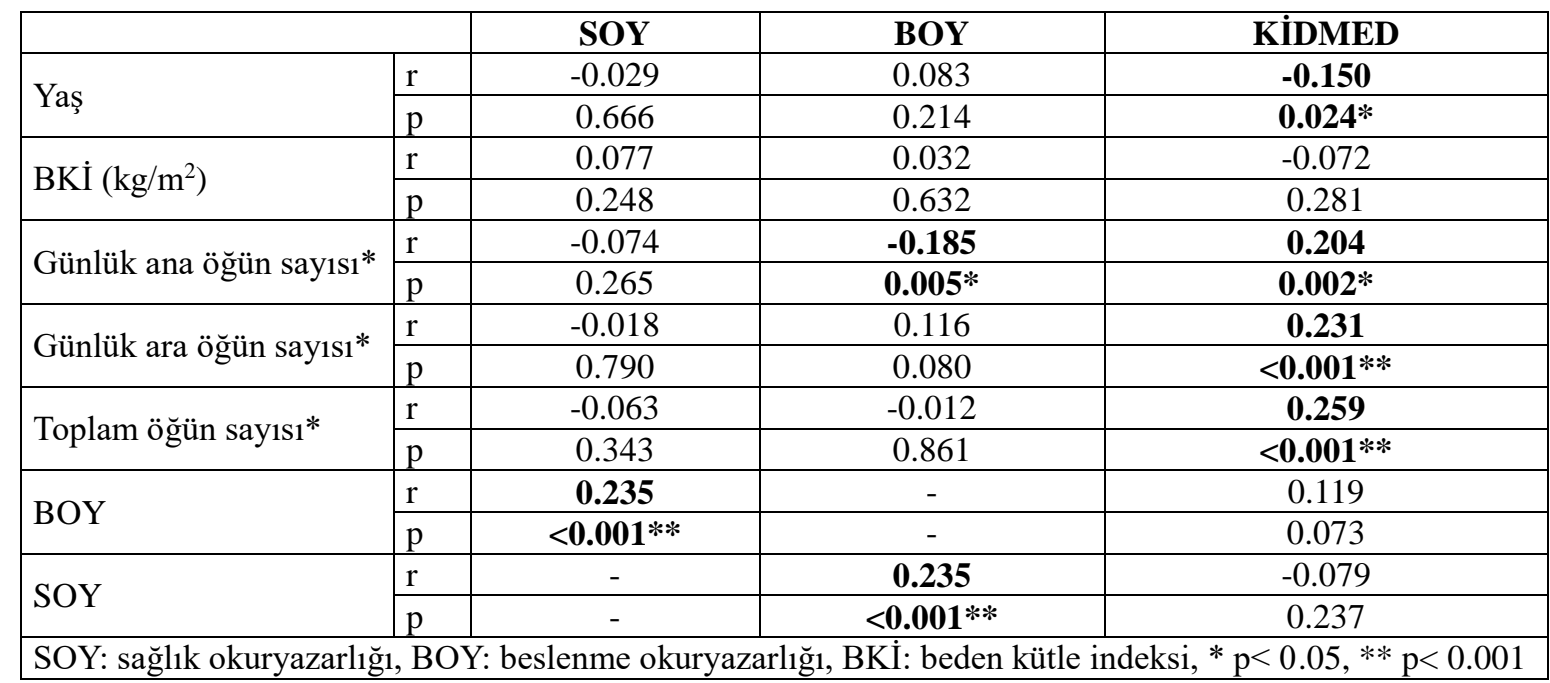


European Journal of Science and Technology

Tablo 5. Diyet kalitesini etkileyen faktörler

\begin{tabular}{|c|c|c|c|c|c|}
\hline & \multicolumn{2}{|c|}{ Standardize olmayan } & \multirow{2}{*}{$\begin{array}{c}\text { Satandardize } \\
\text { Beta }\end{array}$} & \multirow{2}{*}{$\mathrm{t}$} & \multirow{2}{*}{$\mathrm{p}$} \\
\hline & B & Std. hata & & & \\
\hline Sabit & 3.909 & 0.675 & & 5.794 & $<0.001 * *$ \\
\hline Toplam ögün sayısı & 0.369 & 0.108 & 0.217 & 3.401 & 0.001* \\
\hline Düzenli olarak fiziksel aktivite yapma & 0.713 & 0.291 & 0.164 & 2.445 & $0.015 *$ \\
\hline SOY & -0.012 & 0.014 & -0.056 & -0.826 & 0.410 \\
\hline BOY & 0.018 & 0.008 & 0.149 & 2.291 & 0.023* \\
\hline
\end{tabular}

\section{Sonuç}

Sağlık okuryazarlığı ve beslenme okuryazarlığı, global olarak gelişmekte olan önemli ve güncel konulardan birisi olup önemi ülkemizde de gittikçe artmaktadır. Gelişmiş ülkelerdekine benzer olarak, sağlık okuryazarlığına ilişkin verileri ülkemizde de açığa çıkaran ve sağlık okuryazarlığını etkileyen faktörleri belirten çalışmalar yürütülmektedir (Berberoğlu ve ark., 2018; Şahinöz ve ark., 2018). Bu çalışmada da adölesanlarda SOY ve BOY düzeyleri ile aralarındaki ilişki saptanmış olup, bunların diyet kalitesine etkisi belirlenmiştir.

Sağlıklı beslenme, sağlıklı bir hayat ve sağlık hizmetlerinin daha etkili şekilde kullanılabilmesi amacıyla bireylerin BOY ve SOY düzeylerinin arttırılması önemli ve gereklidir. Bu kapsamda toplumsal boyutta kampanyaların düzenlenmesi, broşürlerin dağttılmasının ve televizyonlarda eğitici kamu spotlarına yer verilmesinin etkili olabileceği düşünülmektedir. $\mathrm{Bu}$ uygulamalarda eğitimcilerin alanında uzman sağlık profesyonelleri ve diyetisyenlerden oluşması önemlidir. SOY ve BOY'u etkileyen temel faktörlerin bir tanesi de hem adölesanların hem de ailelerin eğitim durumudur. Bu kapsamda, sağlık ve sağlıklı beslenme derslerinin adölesanların derslerine entegre edilmesi, öğrencilere beslenme önerileri ve takibi yapabilecek bir diyetisyenin düzenli olarak okulda faal olması, ailelerin düzenli aralıklarda düzenlenecek eğitimlere katılmalarının sağlanması, yazılı basın ve medyanın doğru kaynaklar ile sağlık ve beslenme yönlendirmeleri yapması, doğru ve etkili internet kullanıcılığı hakkında adölesanların yönlendirilmesi vb. uygulamalar ile SOY ve BOY'un ve dolayığısı ile sağlığın geliştirilmesinin sağlanabileceği düşünülmektedir. Liteatürde SOY ve BOY ile ilgili araştırmaların eksikliği söz konusudur. Bu çalışmanın sonuçları doğrultusunda, BOY ve SOY'un bir arada değerlendirilmesinin önemi vurgulanmış ve BOY'un SOY'a entegre edileceği çalışmalara 1şık tutulmuş olduğuna inanılmaktadır. Özellikle adölesanların SOY ve BOY düzeylerinin belirlenmesi hakkında yapılacak bilimsel çalışmalar arttırılmalıdır.

\section{Kaynakça}

Ateş Özcan, B., Yeşilkaya, B., Yaldız, N., \& Pehlivan, M. (2020). Factors affecting quality in adolescents: the effect of sociodemographic characteristics and meal consumption. Progress in Nutrition, 22 (4), e2020094.

Bari, N.N. (2012). Nutrition literacy status of adolescent students in Kambala district, Uganda. Oslo and Akershus Univercity College of Applied Sciences. Department of Sciences, Nutrition and Management. Master's Programme in Food, Nutrition and Sciences.

e-ISSN : 2148-2683
Bayındır Gümüş, A., \& Yardımcı, H. (2020). Üniversite öğrencilerinin günlük besin ögesi alımlarının Akdeniz diyeti kalite indeksi (KIDMED) ile ilişsisi. Adıyaman Üniversitesi Sağlık Bilimleri Dergisi, 6(2),167-173.

Berberoğlu, U., Öztürk, O., İnci, M.B., \& Ekerbiçer, H.Ç. (2018). Bir aile sağlı̆ı merkezine kayıtlı 18-65 yaş grubu bireylerdeki sağlı okuryazarlığ 1 durumunun değerlendirilmesi. Sakarya Tıp Dergisi, 8(3), 575-581

Berkman, N.D., Sheridan, S.L., Donahue, K.E., Halpern, D.J., \& Crotty, K. (2011). Low health literacy and health outcomes: an updated systematic review. Ann Intern Med, 155(2), 97107.

Carbone, E.T., \& Gibbs, H.D. (2013). Measuring nutrition literacy: Problems and potential solutions. J Nutr Disorders Ther, 3(1).

Carbone, E.T., \& Zoellner, J.M. (2012). Nutrition and health literacy: a systematic review to inform nutrition research and practice. J Acad Nutr Diet, 112(2), 254-265.

Chang, L.C. (2011). Health literacy, self-reported status and health promoting behaviours for adolescents in Taiwan. Journal of Clinical Nursing, 20(1-2), 190-196.

Dima-Cozma, C., Gavrilută, C., Mitrea, G., \& Cojocaru, D. C. (2014). The importance of healthy lifestyle in modern society: a medical, social and spiritual perspective. Eur J Sci Theol, 10(3), 111-120.

Gibbs, H.D., \& Chapman-Novakofski, K. (2012). Exploring nutrition literacy: Attention to assessment and the skills clients need. Health, 4 (3), 120-124.

Joulaei, H., Keshani, P., \& Kaveh, M.H. (2018). Nutrition literacy as a determinant for diet quality amongst young adolescents: a cross sectional study. Progress in Nutrition, 20(3), 455-464.

Koçak, K., \& Saltuk Demir, L. (2019). Adölesanlarda sağlık okuryazarlı̆̆ı ile riskli sağlık davranışarı arasındaki ilişki, 3 . International 21. National Public Health Congress.

Kolasa, K.M., Peery, A., Harris, \& Shovelin, K. (2001). Food literacy partners program: a strategy to increase community food literacy. Topics in Clinical Nutrition, 16 (4), 1-10.

Kuczmarski, M.F., Adams, E.L., Cotugna, N., Pohlig, R.T., Beydoun, M.A., Zonderman, A.B., \& Evans, M.K. (2016). Health literacy and education predict nutrient quality of diet of socioeconomically diverse, urban adults. Journal of Epidemiology and Preventive Medicine, 2(1).

Malatyalı İ., \& Biçer E. (2018). Sağlık okuryazarlığı düzeyinin belirlenmesi: sivas cumhuriyet üniversitesi örneği, ASHD; 17(2), 16-27.

Manganello, J.A. (2008). Health literacy and adolescents: a framework and agenda for future research. Health Educ Res, 23(5), 840-847.

Mansfield, E., Wahba, R., \& De Grandpré, E. (2020). Integrating 
a health literacy lens into nutrition labelling policy in Canada. Int J Env Res Pub He, 17(11), 4130.

Naeeni, M.M., Jafari, S., Fouladgar, M., Heidari, K., Farajzadegan, Z., Fakhri, M., et al. (2014). Nutritional knowledge, practice, and dietary habits among school children and adolescents. Int J Prev Med, 5(Suppl 2), S171.

Okyay P., \& Abacıgil F. (2016). Türkiye sağlık okuryazarlığı ölçekleri güvenirlililk ve geçerlilik çalışması, Anıl Matbaa. 1. Bask1. Ankara 2016; 43-60.

Quaidoo, E.Y., Ohemeng, A., \& Amankwah-Poku, M. (2018). Sources of nutrition information and level of nutrition knowledge among young adults in the Accra metropolis. BMC Public Health, 18(1), 1-7.

Rodrigues, P.R.M., Luiz, R.R., Monteiro, L.S., Ferreira, M.G., Gonçalves-Silva, R.M.V., \& Pereira, R.A. (2017). Adolescents' unhealthy eating habits are associated with meal skipping. Nutrition, 42, 114-120.

Saribay, A.K., \& Kirbas, S. (2019). Determination of nutrition knowledge of adolescents engaged in sports. Univers J Educ Res, 7(1), 40-47.

Serra-Majem, L., Ribas, L., Ngo, J., Ortega, R.M., Garcia, A., Perez-Rodrigo, C. et al. (2004). Food, youth and the mediterranean diet in spain. Development of KIDMED, mediterranean diet quality index in children and adolescents. Public Health Nutr, 7(7), 931-935.

Silk, K.J., Sherry, J., Winn, B., Keesecker, N., Horodynski, M.A., \& Sayir, A. (2008). Increasing nutrition literacy: testing the effectiveness of print, web site, and game modalities. J Nutr Educ Behav, 40(1), 3-10.

Smith, M.L. (2009). Health literacy and weight-related behaviors among college students. University of Missouri-Kansas City, College of Arts\& Sciences, Department of Psychology, PhD thesis.

Spronk, I., Kullen, C., Burdon, C., \& O'Connor, H. (2014). Relationship between nutrition knowledge and dietary intake. Br J Nutr, 111(10), 1713-1726.

Şahinöz T. ve ark. (2018). Üniversite son sınıf öğrencilerinin sağlık okuryazarlığı düzeyleri üzerine karşılaştırmalı bir araştırma, GÜSBD, 7(3), 71- 79.

Sonay Türkmen, A., Kalkan, İ., \& Filiz, E. (2017). Adölesan beslenme okuryazarlığı ölçeğinin türkçe'ye uyarlanması: geçerlilik ve güvenirlilik çalışması. DBHAD, (10), 1-16.

Vaitkeviciute, R., Ball, L.E., \& Harris, N. (2015). The relationship between food literacy and dietary intake in adolescents: a systematic review. Public Health Nutrition, 18(4), 649-658.

Vidgen, H.A., \& Gallegos, D. (2014). Defining food literacy and its components. Appetite, 76(1), 50-5. 